Beiträge zur Geldlehre 10 herausgegeben von Rudolf Schilcher 



\section{Kreditschöpfung unter Unsicherheit}

Aktivplanung einer Bank und Implikationen für die Übertragung monetärer Impulse

von

Kurt von dem Hagen

$W$
DE
$G$

Walter de Gruyter · Berlin · New York 1975 
Dr. rer. pol. Kurt von dem Hagen

Wiss. Assistent am Lehrstuhl

für Volkswirtschaftslehre und

Statistik der Universität Mannheim

CIP-Kurztitelaufnahme der Deutschen Bibliothek

\section{Hagen, Kurt von dem}

Kreditschöpfung unter Unsicherheit: Aktivplanung e.Bank u.

Implikationen $\mathrm{f}$. $\mathrm{d}$. Übertragung monetärer Impulse.

(Beiträge zur Geldlehre; 10)

ISBN 3110065487

(C) Copyright 1975 by Walter de Gruyter \& Co., vormals G.J. Göschen'sche Verlagshandlung - J. Guttentag, Verlagsbuchhandlung - Georg Reimer - Karl J. Trübner - Veit \& Co mp., Berlin 30. - Alle Rechte, insbesondere das Recht der Vervielfältigung und Verbreitung sowie der Übersetzung, vorbehalten. Kein Teil des Werkes darf in irgendeiner Form (durch Photokopie, Mikrofilm oder ein anderes Verfahren) ohne schriftliche Genehmigung des Verlages reproduziert oder unter Verwendung elektronischer Systeme verarbeitet, vervielfältigt oder verbreitet werden. Printed in Germany. - Druck: Color-Druck, Berlin 49.- Bindearbeiten: Wübben \& Co., Berlin 42. 